\title{
Illinois Pharmacists and Over the Counter Cannabidiol Products: A Survey on Knowledge and Educational Needs
}

\author{
Kayla Link, PharmD/MBA Candidate; Maithili Deshpande, PhD; McKenzie Ferguson, PharmD, BCPS \\ Pharmacy Practice, Southern Illinois University Edwardsville
}

\begin{abstract}
Objective: To assess Illinois pharmacists' (1) baseline knowledge of CBD and self-rated competency of OTC-CBD product pharmacotherapy, (2) concerns about OTC-CBD product safety and level of preparedness with answering questions about the product, and (3) current and future interest in learning more about these types of products to target an area of need for continuing education in the pharmacy field.

Design: This observational cross-sectional study used a quantitative survey to obtain information about Illinois pharmacists' knowledge, concerns and educational needs about OTC-CBD products. Survey questions were based on prior research and pilot tested for clarity and completeness. Descriptive statistics were utilized to assess all data.

Setting and Participants: The study researchers collaborated with two state-based pharmacy organizations to distribute the survey online with up to two reminders.

Results: A total of 181 participants completed the survey. Majority of the respondents were 31-60 years of age, had worked in pharmacy for less than 5 years, in a geographic location with a population of 50,000 or more. About 41\% worked in hospital-based practice setting and 39.2\% work in a community-based setting. Most pharmacists (64.1\%) reported ever being asked about the safety or efficacy of cannabidiol containing products, and only $20.7 \%$ responded that they felt moderately/highly prepared to provide medication counseling to patients who use OTC-CBD products. Majority of respondents reported being concerned about safety, quality, and regulations related to OTC-CBD products. Almost all respondents indicated that information about state (90.5\%) and federal (89.4\%) laws related to CBD, and safety (99.5\%) were preferred topics for future education.

Conclusions: Consumers are seeking information about CBD containing products; however, many pharmacists do not feel prepared when it comes to being the drug expert for these products. Educational opportunities are necessary for pharmacists to become more comfortable and knowledgeable regarding safe and effective use of CBD-OTC containing products.
\end{abstract}

Keywords: CBD, pharmacist, knowledge, OTC, cannabidiol

\section{Background}

Cannabidiol (CBD) is a chemical compound found in cannabis. ${ }^{1}$ CBD has little effect on the intracranial self-stimulation pathway with cannabinoid ${ }_{1}(\mathrm{CB})$ receptors, unlike another component of cannabis, tetrahydrocannabinol (THC). CBD derived from a hemp plant, containing less than $0.3 \%$ THC, is deemed as a relatively safe agent that does not produce the "high" feeling associated with marijuana. Limited evidence from wellcontrolled human experimental research shows that the lower concentration of hemp-derived CBD lacks abusive potential. ${ }^{1,2,3}$ These low concentration, hemp-derived CBD products are available over-the- counter (OTC) in a wide variety of formulations, such as capsules, oil solution, sublingual units, intranasal sprays, and topical preparations. ${ }^{1,4}$

Recently there has been an increased public interest in the use of CBD for a variety of ailments. Early in 2018, then Illinois Governor, Bruce Rauner, signed the Illinois Industrial Hemp Pilot Program into law to allow cultivation of hemp in Illinois. ${ }^{10}$ Later the same year, Congress signed the 2018 Farm Bill, federally legalizing cultivation of hemp nationwide. The bill

Corresponding author: Maithili Deshpande, $\mathrm{PhD}$ 200 University Park Dr, Campus Box 2000

Edwardsville, IL 62026; Email: mdeshpa@siue.edu states that hemp-cultivated CBD must have less than $0.3 \% \mathrm{THC}$ contained in the product. ${ }^{11}$

In 2016, CBD sales in the US were $\$ 170$ million. It is now estimated that sales will continue to trend upwards to over \$1 billion by $2021 .^{12}$ Over the counter (OTC) CBD-containing products are not approved by the Food and Drug Administration (FDA). Therefore, there is no strict regulation on the manufacturing of these products. The lack of FDA approval means that OTC-CBD products cannot be sold as "therapeutic" medication (i.e., drug). ${ }^{13}$ Currently, Epidiolex (manufactured by Greenwich Biosciences) is the only FDA approved prescription CBD-containing product and is dispensed as an oral solution. ${ }^{14}$

Given the widespread availability of OTC-CBD products in pharmacies, pharmacists play an important role in understanding and communicating the impact of using OTCCBD products. Marijuana is still classified as a Schedule I controlled substance in many states, and pharmacy schools incorporate limited discussion of various cannabis products within their curricula. ${ }^{15}$ This is affecting pharmacy students, as well as practicing pharmacists, who have sparse continuing education opportunities for OTC-CBD products. A study of Minnesota registered pharmacists assessed the baseline medical marijuana knowledge, concerns, and preparedness to dispense the products before the state's medical marijuana 
program took effect. ${ }^{16}$ Results of the study showed that pharmacists were not aware of the state-level laws and regulations regarding medical marijuana. Many of them also noted not having enough education on the pharmacokinetics and pharmacodynamics of the products to provide efficient counseling to patients. Further, a small study $(n=34)$ of Australian pharmacists highlighted concern for federal legalization of medical cannabis, including quality of products, long-term safety and abuse profiles, and stigma associated with use. ${ }^{17}$

While these few studies assess the pharmacists' stance on their own capability to manage patients' use of medical marijuana, none have specifically studied OTC-CBD products. Therefore, this study serves the purpose of assessing pharmacists' awareness of the OTC-CBD products.

\section{Objectives}

The objectives of this study are to assess pharmacists' (1) baseline knowledge of CBD and self-rated competency of OTC-CBD product pharmacotherapy, (2) concerns about OTCCBD product safety and level of preparedness with answering questions about the product, and (3) current and future interest in learning more about these types of products to target an area of need for continuing education in the pharmacy field.

\section{Methods}

\section{Study Design}

This observational cross-sectional study used a quantitative survey to collect information about pharmacists' knowledge of OTC-CBD products, their level of preparedness to counsel the patients on OTC-CBD products, as well as their interest in learning more about these products. An email containing a link to the questionnaire was sent to all pharmacists who were members of Illinois Pharmacists Association (IPhA) and/or Illinois Council of Health-System Pharmacists (ICHP). Within the email, information was provided to the participants about study objectives and survey anonymity. It was also explained that the survey is voluntary, and only pharmacists holding an active Illinois pharmacy practice license should participate. Only those consenting to the study had access to the survey. Data was collected through an online survey platform, Qualtrics, from August $15^{\text {th }}, 2019$ to September $30^{\text {th }}, 2019$ with one reminder sent by ICHP (approximately 2 weeks later) and two reminders sent by IPhA (approximately 2 weeks apart).

\section{Survey}

A 20-question survey was assessed for face validity by two Southern Illinois University Edwardsville faculty pharmacists. The survey items were based on previous medical marijuana literature, and were modified to suit the current survey needs. ${ }^{16}$ The initial draft was modified based on faculty feedback and then piloted among four practicing pharmacists. The wording of questions and available responses were revised to improve the flow and readability of the survey. The final survey assessed the pharmacists' demographic information (i.e. age, number of years working as a pharmacist, practice site, setting), objective 1: knowledge about cannabidiol and OTC-CBD products and laws (6 questions given as true/false or multiple choice), selfassessed competency in pharmacotherapy of OTC-CBD products (3 questions on Likert-type scales), objective 2: concerns about safety of OTC-CBD products ( 5 questions on Likert-type scale), and level of preparedness for counseling patients and discussing with health care providers ( 2 questions on Likert-type scales), and objective 3: current and future educational needs (4 questions assessing preference). The final draft of the survey, informed consent form, and methodology were approved by the Institutional Review Board of Southern Illinois University at Edwardsville.

\section{Study Sample}

Current members of IPhA and/or ICHP who had an active Illinois pharmacy practice license and consented to participate in the survey were included in the study. The survey was electronically delivered to 4,368 IPhA members and 538 ICHP members with a total of 181 members responding to the survey. Since an overlap of membership between the two organizations is likely, an accurate denominator, and therefore response rate, could not be calculated.

\section{Statistical Analysis}

Results were summarized with descriptive analysis using Microsoft Excel. Objective 1: knowledge about cannabidiol and OTC-CBD products and laws was assessed as correct/incorrect based on the responses provided, self- assessed competency in pharmacotherapy of OTC-CBD products was assessed using Likert-type scale (strongly competent - strongly incompetent). Objective 2: concerns about safety of OTC-CBD products were assessed using Likert-type scale (no concern - highly concerned), level of preparedness for counseling patients and discussing with health care providers were assessed also using Likert-type scale (not at all prepared - highly prepared). Objective 3: current and future interest in CBD related education was assessed using a preference scale. Likert-type responses were assessed by combining sparse categories (e.g. no concern, slight/somewhat concern, and moderate/high concern).

\section{Results}

\section{Demographics}

A total of 181 pharmacists participated in the survey. Table 1 describes the sample demographics and practice-related experiences of the sample. A majority of the participants were between the ages of 31-60 years old, had worked in pharmacy for less than 5 years, in a geographic location with a population of 50,000 or more. The two most prominent pharmacy workplace settings were hospital (40.9\%) and community (independent-22.1\%; chain-17.1\%). When asked if a patient has ever inquired about the safety or efficacy of OTC-CBD products, 116 pharmacists (64.1\%) reported yes, with $89.6 \%$ of those participants reported having at least one encounter within the previous month. 
Objective 1: Knowledge assessment and Self-rated competency of OTC-CBD product pharmacotherapy

Six content-based questions were asked to the participants that covered OTC-CBD product properties, indications, dosage forms, and laws and regulations (Table 2 and Figures $1 \& 2$ ). In general, participant knowledge about OTC-CBD products was lacking, however, a majority identified that OTC-CBD is not approved by the FDA (Table 2). Incidentally, since the dissemination of this survey, Elixicure, a CBD-infused pain relief product, has been certified by the FDA. This certification is not an indication of the FDA's approval, but allows for the product to be included in the national drug code directory..$^{18}$ Participant knowledge about OTC-CBD scheduling and type of dosage forms was also found to be limited (Figures $1 \& 2$ ). Lastly, a total of $63 \%$ of participants rated themselves as incompetent regarding knowledge of pharmacokinetics and pharmacodynamics of OTC-CBD products (Table 3 ).

Objective 2: Concerns about OTC-CBD product safety and level of preparedness with answering questions about the product

A majority of participants reported being moderately/highly concerned about the consistency in quality of OTC-CBD products $(87.2 \%)$ and the safety of OTC-CBD products (69.4\%). Pharmacists also reported feeling unprepared to discuss OTCCBD products with other health care providers as well as to counsel patients about these products (Table 4).

\section{Objective 3: Current and future continuing education}

Current continuing education was defined as any continuing education credit received within the past two years. A number of pharmacists sought continuing education related to $C B D$ in the past two years (42\%). Participants also reported seeking CBD-related information independently from internet searches (33.3\%), followed by the IPhA (18.6\%). A few participants also reported "other" as a source of information, noting PubMed, employer-provided information, and local/state conferences as sources of information for cannabidiol. (Table 5). OTC-CBD product safety and pharmacotherapy were the most preferred education topics among participants. Online courses and emails were the most preferred method to receive CBD-related information (Figure 3).

\section{Discussion}

Hemp-derived CBD products containing less than $0.3 \% \mathrm{THC}$ are OTC products that have recently surged in popularity. While most previous research focuses on medical marijuana that contains $0.4 \%$ or more THC and requires a prescription, this study focused on the OTC-CBD products which are more likely to be encountered on the shelves of pharmacies. ${ }^{16}$ Since Illinois legalized hemp-derived CBD in 2018, this study is an early assessment of Illinois pharmacists' knowledge and comfort with OTC-CBD products. The findings of this study indicated a lack of knowledge about these products, significant concerns about the safety and quality of these products, lack of preparedness in discussing these products with patients and health care providers and a need for continuing education about CBD products among Illinois pharmacists. This study provides a baseline understanding of Illinois pharmacist OTC-CBD knowledge. A common misconception exists among the general public regarding the potential for euphoric effects from OTCCBD use. OTC-CBD products do not contain a significant amount of THC, reducing the likelihood of causing a euphoric effect in users, and are generally considered safe by the World Health Organization (WHO). ${ }^{1}$ Although $55 \%$ of respondent pharmacists correctly identified this fact, there were still many unaware that OTC-CBD products contain less than $0.3 \%$ THC do not produce a euphoric effect. Additionally, a majority of participants consider OTC-CBD products to be unsafe for use by the general public. Safety and efficacy of these products remains under investigation and there is a lot that is unknown. ${ }^{19}$ OTC-CBD products with less than $0.3 \%$ THC have a low dependency potential and a wide therapeutic index. ${ }^{20}$ Common adverse effects reported include somnolence, fatigue, diarrhea, and lack of appetite. ${ }^{20}$ As this research develops, pharmacists would benefit from targeted OTC-CBD product safety and efficacy information. Another concern is the lack of knowledge of dosage form availability for OTC-CBD products. Although participants identified only one FDA approved dosage form (Epidiolex solution), about $80 \%$ of respondents were unable to identify all OTC-CBD dosage forms on the market. This is problematic when obtaining a medication history from a patient due to not reiterating all forms of medication that may be available for patient purchase OTC.

Many pharmacists report feeling incompetent discussing pharmacokinetics and pharmacodynamics of OTC-CBD products with patients and other health care professionals. Many also identified concerns about quality, consistency, efficacy, and safety of OTC-CBD products. Being a medication expert, counseling patients and talking with other health care providers about medications is a primary role of pharmacists. Not understanding the entire product may leave patients and providers at a disadvantage. Without having the proper knowledge of how these products work, a patient's health may be impacted in the form of adverse events or drug interactions. In general, CBD and THC are known to inhibit cytochrome P450 2C9, an enzyme used in the metabolism of several medications. ${ }^{20}$ For instance, case studies have provided evidence of an increased risk of bleeding when CBD is combined with warfarin. ${ }^{21}$ Comprehensive, large scale studies, however, are lacking which makes it difficult to ascertain clinical significance of the available literature.

A substantial number of participants $(42 \%)$ reported attending CBD-focused continuing education sessions within the past two years. Participants also sought out CBD-focused education independently through internet searches, PubMed, and pharmacy organizations. Additionally, respondents stated that they were interested in receiving further education on CBD, 
specifically pharmacotherapy and safety topics. This clearly indicates the growing demand for CBD product-focused continuing education. While continuing education is being provided at national conferences, it may not be enough to accommodate all pharmacists. ${ }^{22}$ In order to bridge the knowledge gap, continuing education needs to be accessible through a widely available platform, such as an online course.

A strength of this study is the utilization of two large pharmacy organizations from the state of Illinois, which captures a wide variety of pharmacists throughout the state. Additionally, the study sample had pharmacists with a variety of ages, practice sites and level of experience that participated in the survey.

Limitations of this study include small sample size and response rate. Due to the survey going out to two Illinois pharmacist organizations, it is possible that some participants may be a member of both organizations, making it difficult to calculate the true denominator and thus an accurate response rate. Although this survey reached a wide range of participants from different practice sites with varying levels of experience, the small sample size means we cannot eliminate non-response bias. Additionally, pharmacists who are not members of either organization were not surveyed in this study. Lastly, the researchers noted that one knowledge-based question about the most studied indication of OTC-CBD had the correct answer blocked from selection by participants in the online portal. Due to this error, the question was not included in the analysis. In addition, this analysis did not link knowledge to the concerns expressed with OTC-CBD.

\section{Conclusion}

The results of this study suggest that Illinois pharmacists are in need of additional education to be able to adequately assist consumers and health care professionals on OTC-CBD products. A majority of Illinois pharmacists are concerned about the safety and efficacy, and feel unprepared to speak to consumers and other health care providers about OTC-CBD products. Therefore, continuing education targeting federal and state CBD regulations, pharmacotherapy and safety, and available product dosage forms should be made available for pharmacists and other health care professionals practicing in Illinois.

Acknowledgements: We would like to thank the Illinois Pharmacists Association and the Illinois Council of Health System Pharmacists for providing us their member base for our survey.

Conflicts of interest: We declare no conflicts of interest or financial interests that the authors or members of their immediate families have in any product or service discussed in the manuscript, including grants (pending or received), employment, gifts, stock holdings or options, honoraria, consultancies, expert testimony, patents and royalties.
Treatment of Human Subjects: IRB exemption granted

Previous presentations of the work: Part of this work will be presented as a virtual poster at the 2020 American Pharmacists Association Annual Meeting, Washington D.C and at the Southern Illinois University Edwardsville School of Pharmacy Virtual Poster Day 2020.

\section{References}

1. World Health Organization. (2018, June 4). Cannabidol (CBD) Critical Review Report. Retrieved April 8, 2020, from https://www.who.int/medicines/access/controlledsubstances/WHOCBDReportMay2018-2.pdf?ua=1

2. Babalonis S, Haney M, Malcolm RJ, et al. Oral cannabidiol does not produce a signal for abuse liability in frequent marijuana smokers. Drug Alcohol Depend. 2017;172:9-13.

3. Martin-Santos R, Crippa JA, Batalla A, et al. Acute effects of a single, oral dose of d9. tetrahydrocannabinol (THC) and cannabidiol (CBD) administration in healthy volunteers. Curr Pharm Des. 2012;18(32):4966-4979.

4. Cannabidiol products. Canabidol ${ }^{\mathrm{TM}} \mathrm{CBD}$ oil (cannabidiol) - the UK's best selling cannabis supplement. https://canabidol.com/. Retrieved April 8,2020

5. Devinsky O, Cross JH, Laux L, et al. Trial of cannabidiol for drug-resistant seizures in the dravet syndrome. $\mathrm{N}$ Engl J Med. 2017;376(21):2011-2020.

6. Zuardi AW, Crippa JaS, Hallak JEC, et al. Cannabidiol for the treatment of psychosis in parkinson's disease. J Psychopharmacol (Oxford). 2009;23(8):979-983.

7. Watt G, Shang K, Zieba J, et al. Chronic treatment with $50 \mathrm{mg} / \mathrm{kg}$ cannabidiol improves cognition and moderately reduces $A \beta 42$ levels in 12-month-old male A $\beta P$ Pswe/PS1 $\triangle E 9$ transgenic mice. J Alzheimers Dis. 2020.

8. Xu DH, Cullen BD, Tang M, Fang Y. The effectiveness of topical cannabidiol oil in symptomatic relief of peripheral neuropathy of the lower extremities. Curr Pharm Biotechnol. 2019.

9. Zanelati TV, Biojone C, Moreira FA, Guimarães FS, Joca SRL. Antidepressant-like effects of cannabidiol in mice: Possible involvement of 5-HT1A receptors. Br J Pharmacol. 2010;159(1):122-128.

10. Caruso, Vincent. "Rauner Signs Bill Lifting Ban on Industrial Hemp." Illinois Policy, 1 Sept. 2018, www.illinoispolicy.org/rauner-signs-bill-lifting-banon-industrial-hemp/.

11. "2018 Farm Bill." The United States Senate Committee On Agriculture, Nutrition \& Forestry, www.agriculture.senate.gov/2018-farm-bill. 
12. Corroon J, Phillips JA. A cross-sectional study of cannabidiol users. Cannabis Cannabinoid Res. 2018;3(1):152-161.

13. "Hemp and Farm Programs." Hemp and Farm Programs | Farmers.gov, www.farmers.gov/manage/hemp.

14. "EPIDIOLEX ${ }^{\circledR}$ (Cannabidiol) CV." EPIDIOLEX.com, www.epidiolex.com/.

15. Abazia DT, Bridgeman MB. Reefer madness or real medicine? A plea for incorporating medicinal cannabis in pharmacy curricula. Currents in Pharmacy Teaching and Learning. 2018;10(9):1165-1167.

16. Hwang J, Arneson T, St Peter W. Minnesota pharmacists and medical cannabis: A survey of knowledge, concerns, and interest prior to program launch. P \& T : a peer-reviewed journal for formulary management. 2016;41(11):716-722.

17. Isaac S, Saini B, Chaar BB. The role of medicinal cannabis in clinical therapy: Pharmacists' perspectives. PloS one. 2016;11(5):e0155113.

18. "Topical CBD-Infused Pain Relief Product Listing Receives Certification." Pharmacy Times, www.pharmacytimes.com/news/cbd-infused-painrelief-product-receives-fda-certification.

19. Iffland K, Grotenhermen F. An update on safety and side effects of cannabidiol: A review of clinical data and relevant animal studies. Cannabis Cannabinoid Res. 2017;2(1):139-154.

20. Schmitz N, Richert L. Pharmacists and the future of cannabis medicine. Journal of the American Pharmacists Association. 2019;0(0).

21. Damkier $P$, Lassen $D$, Christensen $M M H$, et al. Interaction between warfarin and cannabis. Basic Clin Pharmacol Toxicol. 2019;124(1):28-31.

22. ASHP Midyear Clinical Meeting and Exposition 2019. Full Schedule, Retrieved April 8, 2020, from www.eventscribe.com/2019/midyear/agenda.asp?pf $\mathrm{p}=$ FullSchedule 
Table 1: Sample demographics and characteristics

Sample Demographics and Characteristics

$\mathrm{N}=181$

N (\%)

What is your age range (in years)?

- 22-30

$34(18.8)$

- 31-40

$57(31.5)$

- 41-50

30 (16.6)

- 51-60

$22(12.2)$

- 61-70

- 70+

30 (16.6)

$8(4.4)$

How many years have you worked as a pharmacist?

- Less than 5

39 (21.5)

- 5-10

31 (17.1)

- 11-20

$40(22.1)$

- 21-30

25 (13.8)

- 31-40

21 (11.6)

- 40+

$25(13.8)$

Which of the following areas do you practice in?

- Area with a population of less than 50,0000

49 (27.4)

- Area with a population of 50,000 or more

$102(57)$

- Both

28 (15.6)

What is your primary pharmacy practice setting?^

- Academia

$32(17.7)$

- Community-Independent

40 (22.1)

- Community-Chain

31 (17.1)

- Clinic

$18(9.9)$

- Managed Care

$3(1.7)$

- Hospital

- Hospice/Assisted Living

74 (40.9)

- Industry

$1(0.6)$

$3(1.7)$

- Other

$13(7.2)$

Has a patient ever asked you about the safety or efficacy of cannabidiol (CBD) containing products?

- Yes

$116(64.1)$

- No

65 (35.9)

If yes, how many times in the past month have you been asked by a patient about cannabidiol (CBD) containing products?

- Zero

- 1-2 times

- 3-4 times

- 5+ times

${ }^{\wedge}$ Participants were able to select more than one response on this question. 
Table 2: Knowledge assessment about OTC-CBD products

\begin{tabular}{|c|c|c|c|}
\hline & $\begin{array}{l}\text { Answered } \\
\text { Correctly } \\
\mathbf{N}(\%)\end{array}$ & $\begin{array}{l}\text { Answered } \\
\text { Incorrectly } \\
\text { N (\%) }\end{array}$ & $\begin{array}{l}\text { Unsure } \\
\mathbf{N}(\%)\end{array}$ \\
\hline $\begin{array}{l}\text { It is likely for over the counter cannabidiol (CBD) products that } \\
\text { contain no more than } 0.3 \% \text { tetrahydrocannabinols (THC) to exert } \\
\text { euphoric effects on the user. }\end{array}$ & $99(55.0)$ & $26(14.4)$ & $55(30.6)$ \\
\hline $\begin{array}{l}\text { Over the counter cannabidiol (CBD) containing products (i.e. oils, } \\
\text { topical products, capsules) are FDA-approved products. }\end{array}$ & $163(90.1)$ & $6(3.3)$ & $12(6.6)$ \\
\hline $\begin{array}{l}\text { According to the World Health Organization's Expert Committee on } \\
\text { Drug Dependence, cannabidiol (CBD) is generally well tolerated in } \\
\text { humans with a good safety profile. }\end{array}$ & $79(43.6)$ & $18(9.9)$ & $84(46.4)$ \\
\hline $\begin{array}{l}\text { Under the Federal Controlled Substances Act, cannabis derived } \\
\text { cannabidiol (CBD) prescription drugs that contain no more than } 0.3 \% \\
\text { tetrahydrocannabinols (THC) are classified under what drug } \\
\text { schedule?\# }\end{array}$ & $55(30.1)$ & 126 (69.9\%) & $\mathrm{N} / \mathrm{A}$ \\
\hline $\begin{array}{l}\text { Which of the following are ways in which over the counter } \\
\text { cannabidiol (CBD) is used? }\end{array}$ & $43(23.8)$ & $138(76.2)$ & $\mathrm{N} / \mathrm{A}$ \\
\hline
\end{tabular}

\# More specific responses are available in Figures 1 and 2

Table 3: Self-reported Competency Assessments in pharmacotherapy knowledge of OTC-CBD Products

\begin{tabular}{l|r}
\hline $\begin{array}{l}\text { Rate your competency level in over the counter cannabidiol (CBD) products pharmacotherapy } \\
\text { knowledge in the following areas }\end{array}$ & $\begin{array}{c}\text { Competent } \\
\mathbf{N}(\%)\end{array}$ \\
\hline Pharmacology & $85(47.2)$ \\
Pharmacokinetics & $95(52.8)$ \\
Pharmacodynamics & $65(36.5)$ \\
\hline
\end{tabular}


Table 4: Concerns and level of preparedness about OTC-CBD products

\begin{tabular}{|c|c|c|c|}
\hline Concerns & $\begin{array}{l}\text { No Concern } \\
\quad \mathbf{N}(\%)\end{array}$ & $\begin{array}{l}\text { Slightly/ Somewhat } \\
\text { Concerned } \\
\text { N (\%) }\end{array}$ & $\begin{array}{c}\text { Moderately/ Highly } \\
\text { Concerned } \\
\mathrm{N}(\%) \\
\end{array}$ \\
\hline $\begin{array}{l}\text { Safety of OTC CBD products use (ex: drug } \\
\text { interactions, contraindications, and adverse } \\
\text { reactions) }\end{array}$ & $5(2.8)$ & $61(33.7)$ & $115(63.5)$ \\
\hline Consistency in quality of OTC CBD products & $3(1.7)$ & 20 (11.1) & $157(87.2)$ \\
\hline $\begin{array}{l}\text { Federal regulation related to OTC CBD } \\
\text { products }\end{array}$ & $7(3.9)$ & $49(27.2)$ & $124(68.9)$ \\
\hline $\begin{array}{l}\text { Psychoactive effect and potential addiction } \\
\text { from OTC CBD products }\end{array}$ & $42(23.5)$ & $73(40.8)$ & $64(35.8)$ \\
\hline $\begin{array}{l}\text { Limited evidence of therapeutic benefits from } \\
\text { OTC CBD products }\end{array}$ & $14(7.8)$ & $41(22.8)$ & $125(69.4)$ \\
\hline Level of Preparedness & $\begin{array}{l}\text { Not Prepared } \\
\text { N (\%) }\end{array}$ & $\begin{array}{c}\text { Slightly/ Somewhat } \\
\text { Prepared } \\
\text { N (\%) }\end{array}$ & $\begin{array}{c}\text { Moderately/ Highly } \\
\text { Prepared } \\
\text { N (\%) }\end{array}$ \\
\hline Counseling patients about OTC-CBD products & $72(40.2)$ & $70(39.1)$ & $37(20.7)$ \\
\hline $\begin{array}{l}\text { Discussing OTC-CBD with a health care } \\
\text { provider }\end{array}$ & $69(38.5)$ & $72(40.2)$ & $38(21.3)$ \\
\hline
\end{tabular}

Table 5: Current cannabidiol education sought by survey participants

\begin{tabular}{l|c}
\hline & $\mathbf{N}(\%)$ \\
\hline Continuing education obtained for cannabidiol in past 2 years & 75 (42.0) \\
Current primary resource for information for cannabidiol^ & $23(13.0)$ \\
- Illinois Board of Pharmacy & $12(6.8)$ \\
- Illinois Department of Health & $33(18.6)$ \\
- Illinois Pharmacist Association & $59(33.3)$ \\
- Internet Searches & $19(10.7)$ \\
- U. S. Food and Drug Administration & $4(2.3)$ \\
\hline
\end{tabular}

$\wedge$ Participants were able to select more than one response on this question. 
Figure 1: Knowledge about prescription CBD products that are FDA approved

Under the Federal Controlled Substances Act, cannabis derived cannabidiol

(CBD) prescription drugs that contain no more than $0.3 \%$

tetrahydrocannabinols (THC) are classified under what drug schedule?

Correct response: Schedule V (30\%)

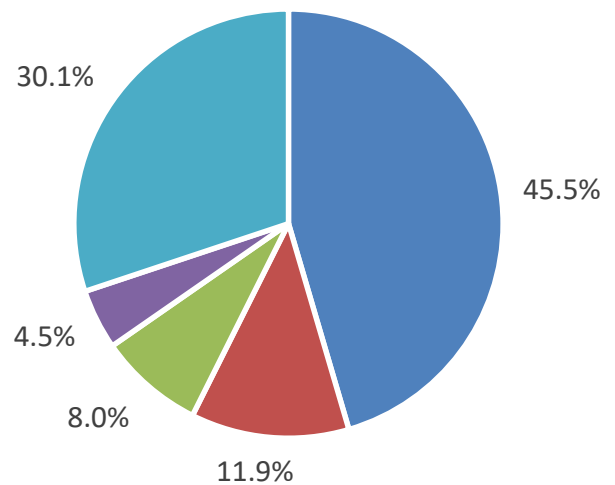

- Schedule I - Schedule II $\square$ Schedule III - Schedule IV - Schedule V

Figure 2: Which of the following are ways in which OTC-CBD is used?

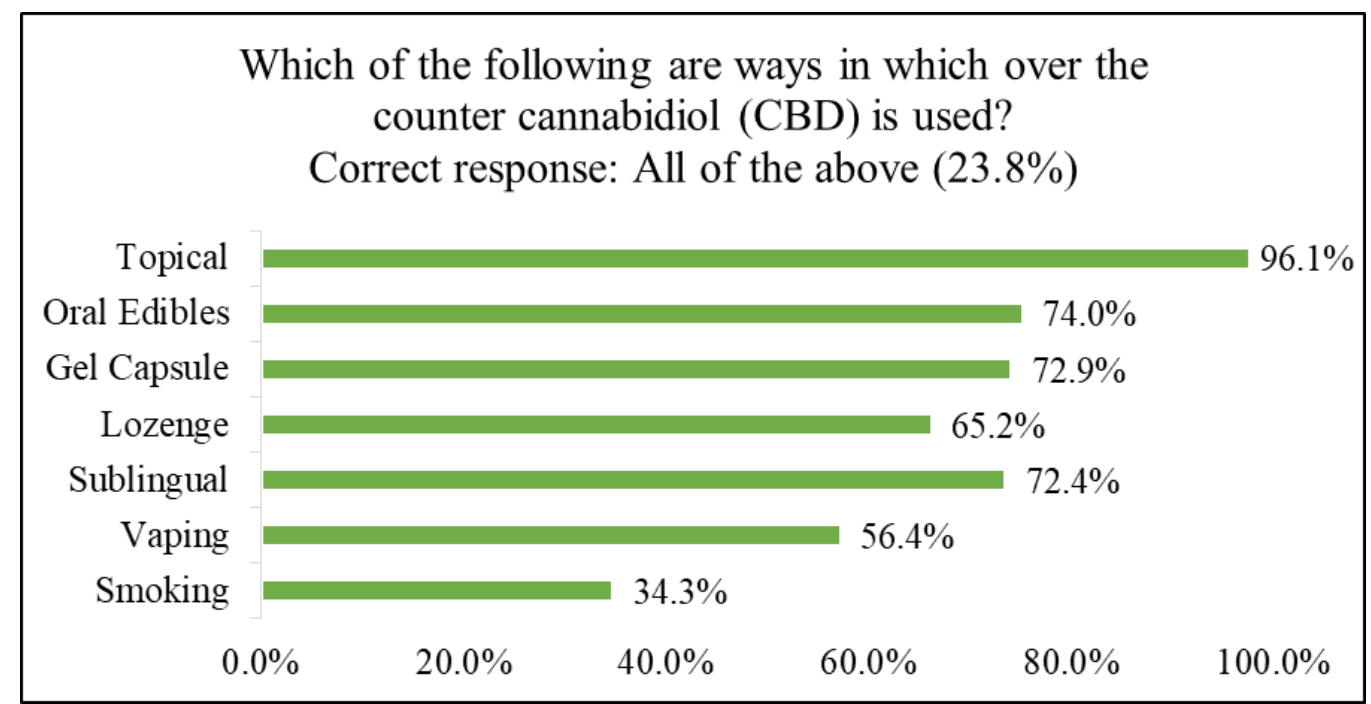


Figure 3: Interest in future CBD education and its method of delivery

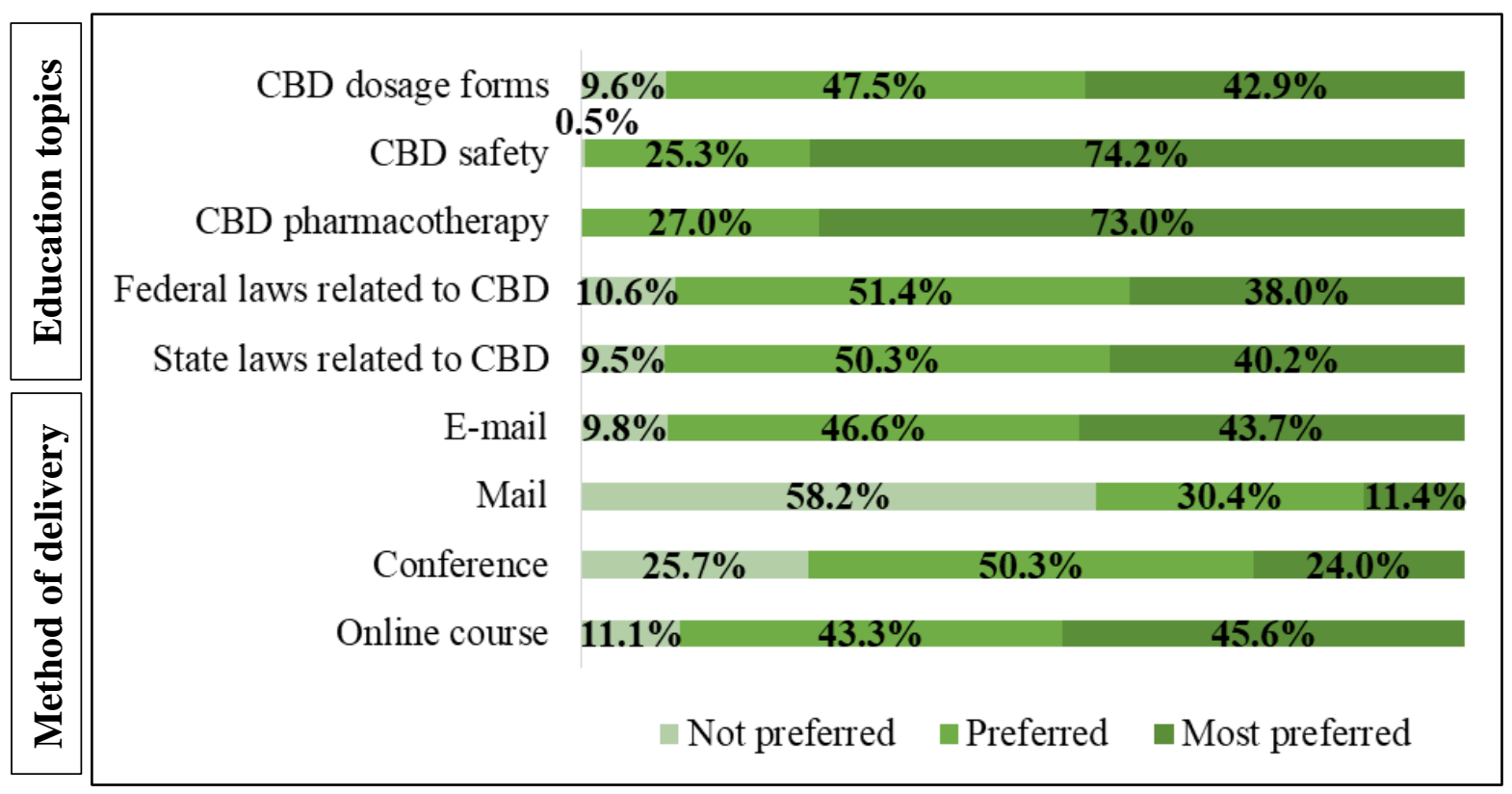

